\title{
Visualização do maguezal para a Plataforma Multiusuário Estação Carijós Estruturas participativas alimentadas pelas coletas nos sítios físico e no da Internet.
}

Yara Rondon Guasque Araujo- DAP- PPGAV. Hermes Renato Hildebrand, UNICAMP, Multimeios; participantes externos: Silvia Regina Guadagnini (ex-PPGAV) e Fabian Silva Antunes (ex-Bacharelado de Artes Plásticas).

\author{
Palavras-chave: plataforma multiusuário; sistema embarcado; participação da \\ comunidade \\ local.
}

Resumo:

Trata-se de um projeto de realidade mista que pela limitação orçamentária se restringiu neste primeiro momento em construir uma planta baixa na Internet. A planta baixa, modelada em flash está sendo preenchida com os dados das coletas de imagens fixas e vídeos realizadas no espaço físico do Manguezal Ratones. Este material serviu neste primeiro momento para demonstrar como um dos participantes acrescentaria dados de sua exploração no espaço físico à planta baixa da área do Manguezal na Internet.

O projeto Visualização do maguezal para a Plataforma Multiusuário Estação Carijós constou como primeira etapa do jogo participativo de realidade mista a ser desenvolvido sob o nome Plataforma Multiusuário Estação Carijós.

Nesta primeira etapa como Visualização do maguezal para a Plataforma Multiusuário Estação Carijós tivemos de redimensioná-lo às possibilidades tecnológicas e à falta de recursos, pois o projeto não obteve ajuda financeira, nem a colaboração de outros laboratórios quanto à execução.

DAPesquisa, Florianópolis, v.3 n.5, p.441-449, 2008. 
Visualização do maguezal para a Plataforma Multiusuário Estação Carijós não pode contar com o consórcio de laboratórios da UFSC, que compunham o projeto integrado multiusuário AMBIENTES INTERATIVOS E IMERSIVOS, que não foi contemplado pelo edital universal, e não obteve os recursos para a aquisição dos aparelhos.

A colaboração da pesquisa teórico-prática se deu num primeiro momento entre os membros integrantes do projeto maior que é o do jogo Plataforma Multiusuário Estação Carijós: Yara Guasque, Hermes Renato Hildebrand, Silvia Guadagnini, Fabian Antunes Silva, Fabiano Luiz Santos Garcia da Mediasoft Softwares e Produções Multimídia Ltda e o Laboratório Integrado de Software e Hardware, LISHA, da UFSC. O objetivo foi delinear as dificuldades técnicas da plataforma multiusuário e do sistema embarcado, com as micro-estações de sensoriamento e as 19 letras que encapsulam as "Tags", RFID (Radio Frequency Identification), Foi realizado para esta etapa um vídeo (http://www.youtube.com/watch?v=4yz2wPT_0XQ ) com dados recolhidos da Internet do googleearth e das capturas coletadas da área do Manguezal Ratones no norte da ilha de Florianópolis. A área compreende a Estação Ecológica dos Carijós, a Reserva do Olandi e a enseada do Ratones. Também foi publicado um texto do projeto como GUASQUE, Y.; HILDEBRAND, H.; GUADAGNINI, S.; e outros. "Plataforma Multiusuário Estação Carijós”. In: VENTURELLI, Suzete (Org.). Arte e intersecções entre arte e pesquisas tecno-científicas, Brasília, 2007, PP. 329-332; o texto foi apresentado no $6^{\circ}$ Encontro Internacional de Arte e Tecnologia: interseções entre arte e pesquisas tecno-científicas, realizado na Universidade de Brasília/Espaço Cultural da 508 Sul em maio de 2007.

Num segundo momento, já com uma equipe mais reduzida, o delineamos de forma mais aberta dada à inexistência de recursos que garantissem subsídios até mesmo à participação do LISHA e da Mediasoft e por reconhecermos a inovação e a importância do desafio em construir uma tal estrutura que tem como meta a conscientização ecológica. Nesta segunda etapa, que teve a participação de Yara Guasque, Hermes

DAPesquisa, Florianópolis, v.3 n.5, p.441-449, 2008. 
Renato Hildebrand, Silvia Guadagnini e Fabian Antunes Silva, pensamos como relevante a participação aberta da comunidade onde o sistema embarcado será implantado e a possibilidade de que o projeto possa ser executado por outras equipes e instalado em qualquer outro manguezal. O projeto em nossa concepção atual pode até mesmo ser executado parcialmente em países diferentes, sendo a plataforma abrigada em uma instituição de país diferente da do sistema embarcado. A publicação e a participação em eventos nacionais e internacionais, como o $6^{\circ}$ Encontro Internacional de Arte e Tecnologia de Brasília de 2007 e em julho agora no ISEA 2008 em Cingapura, confirmam o interesse em divulgar os resultados obtidos.

Mesmo sem os recursos hápticos do capacete de realidade virtual, HMD, previstos no projeto original quando havia a possibilidade da formação do consórcio de laboratórios entre as universidades Federal de Santa Catarina, UFSC, e Estadual de Santa Catarina, UDESC, a visualização do Manguezal Ratones foi realizada elaborando-se uma planta baixa da área do Manguezal sob a qual foram disponibilizados arquivos de áudio, vídeo e de imagens fixas capturados no sítio físico do manguezal (WWW.tecnologiadormente.com/carijos).

Para a captura das imagens e dos vídeos foram realizadas anteriormente várias excursões ao Ratones em sua alça natural, em sua retificação, na enseada do Ratones, em seus afluentes como o Veríssimo; e nos morros da redondeza para se ter um panorama da área. Foram também necessárias várias consultas aos órgãos competentes, Ibama e Ipuf, pesquisando sobre a existência de mapas antigos e atuais da região. Estes mapas mostram dados da bacia hidrográfica da região do manguezal Ratones. Outras foram as incursões na Internet realizando buscas no site da Estação Ecológica Carijós, no do Ibama, no do Instituto Chico Mendes, no da Conservation International do Brasil, no dos arquivos da ECO 92, no do INPE e no googleearth. As coletas de dados na região do espaço físico do Manguezal se deram entre os anos de 2007 (outono) e 2008 (verão). O objetivo das explorações em loco, por água, com um caiaque percorrendo os rios Veríssimo, Ratones em sua alça natural e o Ratones em sua retificação, é propiciar a experiência concreta e o conhecimento sobre a fauna, a flora e o ecosistema,e as

DAPesquisa, Florianópolis, v.3 n.5, p.441-449, 2008. 
ameaças que fragilizam seu equilíbrio, que vivenciadas desta forma se tornam menos abstratas. O resultado destas capturas realizadas na exploração do sítio físico é disponibilizado no site WWW.tecnologiadormente.com/carijos como sendo uma coleta realizada por um dos participantes.

Em uma futura empreitada está a necessidade da construção da plataforma multiusuário com o banco de dados. A plataforma multiusuário junto ao banco de dados garantirá uma participação a multiusuários mais dinâmica. Outra é a implantação do sistema embarcado no espaço físico do Manguezal Ratones. O sistema embarcado consiste nas letras da frase Mar Mermorial Dinâmico como esculturas realizadas em material ecologicamente aprovado que encapsulam as "Tags", RFID (Radio Frequency Identification). As letras serão inseridas na área do manguezal e deverão, como estratégia do jogo, ser capturadas nas coletas de dados que os participantes farão em suas explorações do espaço físico do manguezal.

Será necessário pesquisar material ecológico das letras que não agrida o meio-ambiente, e que se ingerido pelos animais não ameace a saúde dos mesmos, e que ainda não bloqueie que os dados das Tags sejam transmitidos via rádio; averiguar $\mathrm{o}$ funcionamento da plataforma com seu banco de dados e a dinâmica e acesso que a estrutura permite aos multisuários; averiguar o funcionamento e diálogo entre as três micro-estações de sensoriamento e as 19 Tags encapsuladas como letras do sistema embarcado. Todos estes sistemas de forma integrada garantirão uma dinâmica ao entrecruzamento das ações dos participantes nos dois espaços: o virtual da plataforma multiusuário e o do espaço físico do manguezal que terá implantado um sistema embarcado.

O projeto a ser ainda realizado é um jogo participativo de realidade mista que utiliza os espaços físico, com um sistema embarcado, e virtual da Internet com uma plataforma multiusuário junto a um banco de dados. O jogo é de caráter permanente enquanto plataforma multiusuário, e temporário enquanto evento, e tem como metas: a localização das dezenove unidades identificáveis RFID encapsuladas como letras que 
compõem a frase Mar Memorial Dinâmico (M-A-R- M-E-M-O-R-I-A-L-D-I-N-Â-M-IC-O ) dispersas no manguezal, o abastecimento do banco de dados e o mapeamento da área do manguezal. A área do manguezal, onde será implantado o sistema embarcado, será escolhida pela população local e institutos de pesquisa que abriguem o projeto. $\mathrm{O}$ diálogo entre a população local e o instituto que abrigará o projeto é necessário, pois admitimos que o projeto com a plataforma multiusuário e o banco de dados seja hospedado em instituição de região diferente da do sistema embarcado, que pode ser implantado em outro estado ou mesmo noutro país. Por ora estimamos que a área da Reserva do Olandi, no norte de Florianópolis e que pertence ao grupo HABITASUL empreendimentos imobiliários, seja a melhor opção para a implantação do sistema embarcado.

O jogo objetiva a educação ambiental, a conscientização ecológica e da necessidade de preservação do ecossistema. Os participantes são representados na plataforma multiusuário por avatares da fauna local.

Histórico do projeto

Dois outros projetos de autoria de Yara Guasque foram a base poética conceitual do atual Visualização do maguezal para a Plataforma Multiusuário Estação Carijós: a performance Mar como Morte de 1998 e o projeto Mar como sistema de escrita dinâmica de 2005. O projeto Mar como sistema de escrita dinâmica, projeto do qual o atual deriva, procurava com a mesma estrutura de jogo participativo de realidade mista pesquisar os sistemas não-lineares como suporte da escrita e a ação dos fenômenos naturais como processo de co-autoria, além de objetivar também a educação ambiental através da experiência de imersão no sítio físico. A alimentação do espaço virtual do site seria também co-autorada pelos participantes, que usando comunicação móvel junto à tecnologia do Global Positioning System (GPS) enviariam as imagens realizadas. A investigação priorizaria ainda a intersecção e a imersão nos espaços virtual e físico e colocaria a posição física como uma variável importante dos ambientes virtuais. 
Mar como sistema de escrita dinâmica teve ainda na performance de Yara Guasque Mar como Morte de 1998 um começo. A performance ocorrida na Lagoa da Conceição em 1998 espalhou letras esculpidas em material flutante. As letras formavam a frase Mar como Morte e eram embaralhadas pela correnteza e pelo vento. Semanas depois de largadas na Lagoa as letras foram capturadas por transeuntes da região e fotografadas. $\mathrm{Na}$ época uma estrutura de monitoramento dos ventos e das correntes da água teria enriquecido muito o projeto.

Da performance Mar como Morte para o projeto Mar como sistema de escrita dinâmica para depois chegar ao atual Visualização do maguezal para a Plataforma Multiusuário Estação Carijós muitas mudanças ocorreram. A frase Mar como Morte foi substituída para Mar Memorial Dinâmico pela influência dos demais participantes :Hermes Renato Hildebrand, Silvia Guadagnini e Fabian Silva Antunes. E o delineamento da plataforma multiusuário como uma planta baixa a ser preenchida pelos usuários e o detalhamento do sistema embarcado só foi possível com a participação dos demais pesquisadores como Fabiano Luis Santos Garcia da Mediasoft Softwares e Produções Multimídia Ltda e o Laboratório Integrado de Software e Hardware, LISHA, da UFSC.

Mas antes da participação de outros pesquisadores no projeto, outro fator predominante para o delineamento do uso da tecnologia móvel criando um site de monitoramento do meio ambiente veio da admiração da pesquisa realizada por Alexine Keuroghlian e Donald Eaton. O insight ocorreu em 2003 quando descansando no pantanal do Mato Grosso do Sul após minha defesa de tese de doutoramento soube que a Conservation International havia adquirido a Fazenda Rio Negro, que pertencia a um de meus familiares. A Fazenda havia se tornado um modelo para o desenvolvimento de pesquisas científicas e para as atividades de ecoturismo. Estes dois cientistas realizavam pesquisas na região do Pantanal do Rio Negro: Alexine Keuroghlian que pesquisava a resposta à mudança das estações dos porcos do mato no Pantanal do Rio Negro; e Donald Eaton que pesquisava a conservação dos peixes e invertebrados das regiões

DAPesquisa, Florianópolis, v.3 n.5, p.441-449, 2008. 
pantaneiras. Ambos foram patrocinados pela Ford Motor Company Fund. Alexine Keuroghlian usou tecnologias de ponta, como telemetria para monitoramento por rádio dos movimentos dos porcos do mato, associada à observação direta no estudo experimental do comportamento e dos hábitos alimentares deste animal selvagem.

A estrutura de que o banco de dados deveria tornar o conhecimento acessível à população local e se possível ter a participação da comunidade na elaboração do design e na construção da mesma veio das discussões amadurecidas durante a ECO 92.

\section{Concluindo}

Na revisão bibliográfica em Grau, Dixon, Popper, Chlander e Wilson encontramos inúmeros projetos de jogos de realidade mista que se utilizam da tecnologia da comunicação móvel e do GPS alternando entre a realidade e a virtualidade. Em Milgram que é um clássico encontramos os fundamentos do continuum entre estas duas esferas: a virtual e a real. Como também na Internet nos deparamos com não poucos projetos que se utilizam de referências de localização espacial. O Mobilefest que aconteceu em São Paulo em 2007 mostra o enorme interesse em projetos desta natureza.

Entretanto para o encaminhamento do projeto e concretização das etapas foi necessário dividi-lo em partes considerando os níveis de dificuldades e nos atermos ás possibilidades iniciais.

Assim as capturas tiveram que ser editadas em mini clips para depois serem convertidas em formatos mais leves como o FLV que podem ser acessados na Internet. Na Internet WWW.tecnologiadormente.com/carijos a planta baixa começou a ser povoada com os arquivos de vídeo e de imagens fixas das explorações realizadas na área como se fosse as de um participante. Neste estágio não foi possível a criação do banco de dados que permitiria uma estrutura mais dinâmica e uma participação mais aberta, com mais participantes depositando suas coletas no banco de dados da plataforma.

DAPesquisa, Florianópolis, v.3 n.5, p.441-449, 2008. 
Referências bibliográficas:

ARAUJO, Yara Rondon Guasque. Telepresença: interação e interfaces. São Paulo: Educ, 2005.

CHLANDER, Annmarie. NEUMARK, Norie (Editors). At a Distance. Massachusetts, London, England: The MIT Press, 2006.

DIXON, Steve. Digital Performance. A History of New Media in Theater, Dance, Performance Art, and Installation. Cambridge, Massachusetts, London, England: The MIT Press, 2007.

EATON, Donald. The conservation of freshwater invertebrates and fishes in Brazil's Pantanal wetlands. In: Research Proposals. The Earthwatch Institute Conservation. Saving The Pantanal. Accessado online em 2003.

GRAU, Oliver. Arte Virtual: da ilusão à imersão.São Paulo: Unesp/Senac, 2007.

KEUROGHLIAN, Alexine. The response of peccaries to seasonal fluctuation in the Pantanal of Rio Negro. In: Research Proposals. The Earthwatch Institute Conservation. Saving The Pantanal. Accessado online em 2003.

KRUEGER, Myron; TURNER, Jeremy. "Myron Krueger live: Myron Krueger in conversation with Jeremy Turner". In: KROKER, Arthur \& Marilouise. Life in the wires. Victoria: Ctheory Books, 2004.

MILGRAM, Paul; TAKEMURA, Haruo; UTSUMI, Akira; KISHINO, Fumio.

Augmented Reality: A class of displays on the reality-virtuality continuum. In: 282 / SPIE Vol. 2351, Telemanipulator and Telepresence Technologies, 1994. 
NOVAES, Washington. Eco-92: avanços e interrogações. In: SCIELO. Estudos Avançados. Vol. 6 no. 15 São Paulo June 1992. Acessado em http://www.scielo.br/scielo.php?script=sci_arttext\&pid=S0103-40141992000200005.

PACKER, Randall. Multimedia: From Wagner to Virtual Reality. Co-edição Packer, Randall; Jordan, Ken. Versão disponibilizada online: http://www.artmuseum.net/w2vr/timeline, 2001.

POPPER, Frank. From Technological to Virtual Art. Cambridge, Massachusetts, London, England: The MIT Press, 2007.

ROBERTSON, Barbara. Immersed in art: Artists use caves and other VR displays to explore interactive environments. Acessado online.

http://cgw.pennnet.com/Articles/Article_Display.cfm?Section=Archives\&Subsection=D isplay\&ARTICLE_ID $=126854$

SLATER, Mel. (Ed.). Information Society for Presence Research. The $8^{\text {th }}$ International Workshop on Presence. PRESENCE 2005. Conference Proceedings. Department of Computer Science. University College London. Arquivo PDF disponibilizado online, 2005.

ST. JOHN, Warren. Quick after him: Pac-man went thataway. Artigo publicado no $\begin{array}{lllllll}\text { NYTimes no dia } & 9 & \text { de } & \text { maio }\end{array}$ http://www.nytimes.com/2004/05/09/fashion/09GAME.html?th, 2004.

STAPLETON, Christopher; HUGHES, Charles; MOSHELL, Michael; MICIKEVICIUS, Paulius; e ALTMAN, Marty. Applying Mixed reality to Entertainment. In: Entertainment Computing. Versão online, 2002.

WILSON, Stephen. Information, Arts: intersections of art, science and technology. Cambridge, Massachusetts: The MIT Press, 2002.

DAPesquisa, Florianópolis, v.3 n.5, p.441-449, 2008. 